\title{
Design and Implementation of Agricultural Information Service Platform based on Resource Integration
}

\author{
Hongyan $\mathrm{Wu}$ \\ Weifang University of Science and Technology, \\ Shouguang,Weifang,Shandong, 262700 China
}

\begin{abstract}
This paper discusses the design and key technology of digital agriculture spatial information management platform system. The long-term goal of the article is based on the construction of digital agriculture and agricultural informatization, and puts forward the overall framework and structure of digital agriculture spatial information management platform. At the same time, the article puts forward 10 specific individual key technologies of digital agriculture spatial information management platform from the micro level; they constitute the key technologies of digital agriculture spatial information management platform system.
\end{abstract}

KEYWORDS: Digital agriculture; Spatial information management platform; GIS; Agricultural information; Web Service;

\section{INTRODUCTION}

Agriculture is national economy and an important part of the basic industry. Agricultural and rural information related to the sustained and rapid development of the national economy, which is the focus of the national informatization development. At present, the level of agricultural information service has been improved, but the overall level of information is low in rural areas. To accelerate the construction of informationization and improve the level of agricultural information service is imminent. Therefore, construction of agricultural information service platform to promote the agricultural informationization construction in China has a certain theoretical and practical significance.
This paper analyzes the necessity and significance of the agricultural information service from the development of social background, economic background and context of the policy. The article reviews the research status of agricultural information service at home and abroad, the paper summarized respectively from different aspects of agricultural information service theory study, model study, the demand research, supply research and evaluation research and service platform research were. Then the paper carry out systematic research on the basis of agricultural information service.

\section{The overall framework and structure of digital agriculture spatial information management platform}

Digital agriculture spatial information management platform is the core status in the construction of digital agriculture, its development goals: using advanced $3 \mathrm{~S}$ and spatial database technology, take the computer network as the basis, taking the database as the core, to establish a set of RS, GIS, GPS, MIS and ES technology in accurate, efficient, rapid, comprehensive, standardized digital agriculture spatial information management platform. To make full use of the advantages of GIS technique, and the agricultural resource information collection, dynamic monitoring, analysis, management, decision-making and management of spatial information integration, intuitive, image, dynamic display the spatial distribution of agricultural resources status and trend of change. We analyze the relationship between agricultural sustainable development and agricultural economic factors on 
agricultural production and distribution to make scientific and reasonable analysis and evaluation, means of agricultural decision-making departments, administrative departments and relevant agencies to provide agricultural resources management and decision support, it can provides a full range of agricultural geographical information service for the society, to improve standardized level of scientific agricultural work.
According to the principle of advanced, practicality, safety and reliability, openness, scalability and flexibility, protection of existing resources and platform construction, based on to the long-term goal of the construction of digital agriculture and agricultural informatization, propose the hierarchical implementation solution of digital agricultural spatial information management platform, the overall frame is as shown in figure 1.

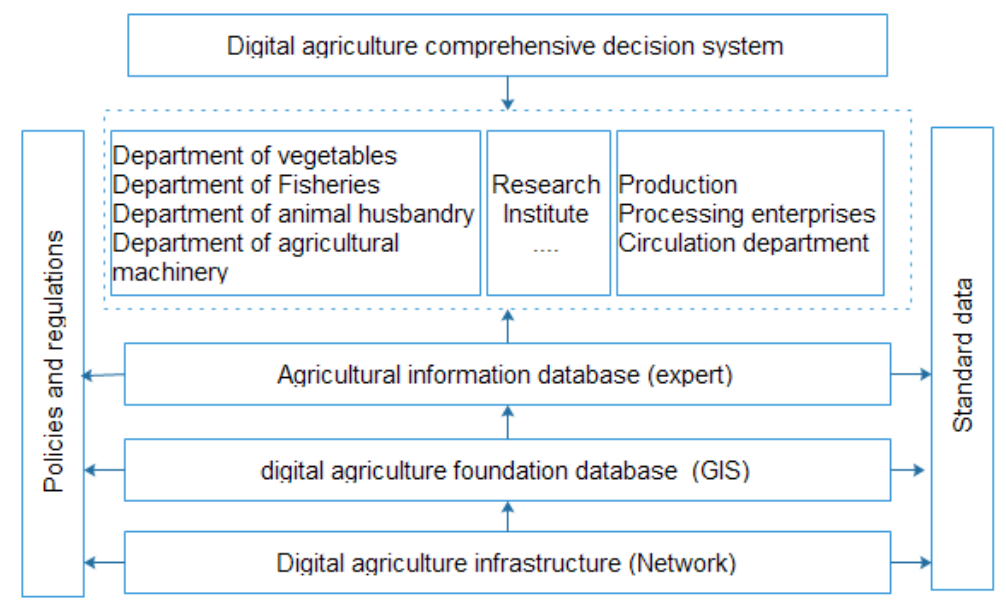

Fig. 1 The overall framework of digital agricultural platform

We should focus on the "three platform". The "three platform" refers to the spatial data platform, network infrastructure platform, application service platform. The network infrastructure platform provides the hardware platform of information exchange and communication, is the foundation of the distributed spatial data sharing and maintenance of hardware. Spatial data platform enable basic geographic data (spatial data) centralized storage, distributed maintenance, and agriculture related business data (attribute) data is distributed data acquisition and distributed maintenance, hierarchical storage and application of association, authorized sharing. Application service platform that support standard data achieve the three major systems application service function on information transmission, service and sharing, strengthen the system of agricultural information, agricultural decision support system, and agricultural monitoring system etc.

Construction of digital agriculture spatial information management platform use WebGIS technology, GPS technology, real-time control technology, web services technology, decision model and expert system, central nervous control model of the system integration technology, the cross knowledge in agriculture, geographical information science, computer science, cybernetics and so on many fields, the use of systems engineering thinking, line, compartmentalized integration, unified standards, unified GIS software platform selection, based on network data coupling, dynamic integration, real-time monitoring. The overall structure of the platform shown in figure 2. 


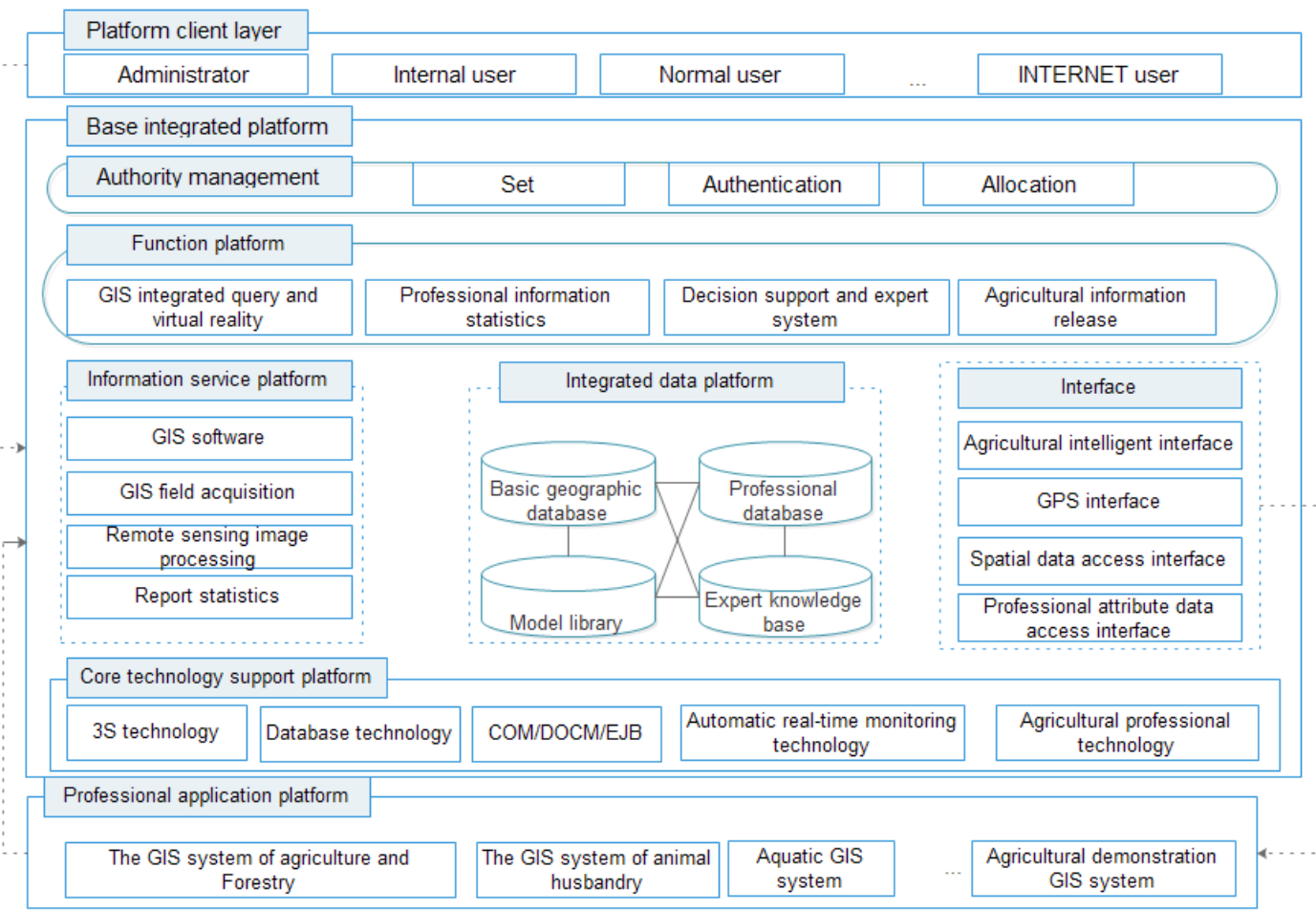

Fig.2 The overall structure of digital agriculture spatial information management platform

\section{The key technology of the platform}

\subsection{Intelligent agricultural machine distributed control system based on GIS}

The intelligent agricultural machinery is concept that fully understand the job content and work scope through the GPS dynamic positioning and wireless communication technology, using computer network and information system, expert system resources by the operator to achieve precision farming, in order to achieve yield efficient agricultural machinery operation target.

The computer network is the foundation of agricultural machinery operation control system. Distributed control system is $4 \mathrm{C}$ technology that is Computer, Controller, Communication technology and CRT technology combined with the product. Also known as total distributed control system or distributed microprocessor control system, it take a microcomputer as the core using unit combination, according to the different needs to combine the flexible complete system, namely, basic controller is a core microcomputer. The basic controller linked together to form the whole system through the data channel and monitoring computer, CRT operation station, its control and structure is shown in Figure 3.

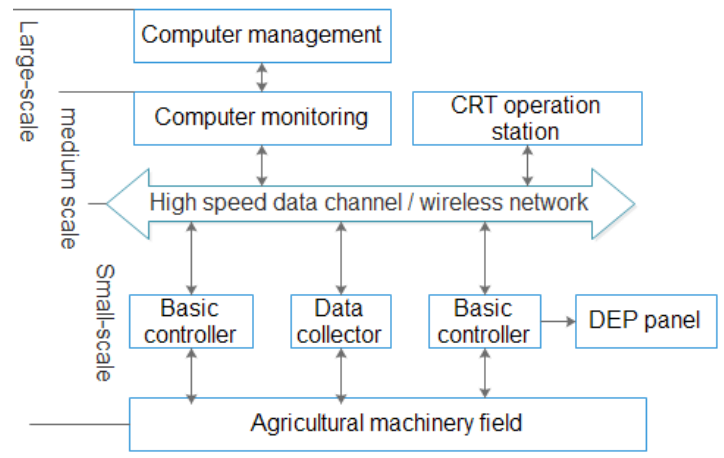

Fig.3 Distributed control system of agricultural machinery

\subsection{Agricultural ecological environment and agricultural products safety auxiliary analysis and decision system based on the GIS}

Agricultural ecological environment and agricultural products safety data analysis and decision system based on the GIS is establish on 
geo spatial database, take map as the information carrier, which can analyze things dynamic rule by geography model, the spatial relationship of the computer system. Therefore, the combination of GIS and DSS is the international study trend of decision support system in recent years.

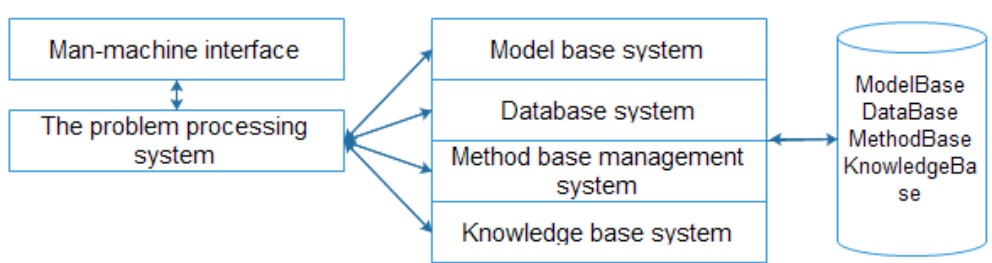

Fig.4 Agricultural ecological environment and agricultural products safety auxiliary analysis and decision system based on the GIS

\subsection{The development of e-commerce platform and collecting information promulgation based on WebGIS}

The geographic information system (GIS) link original management information system, it can gather the agricultural products in the market purchase, sales and inventory data information and agricultural products customer basic information and customer service record, make full use of GIS visualization display, data analysis of cartographic generalization, comprehensive, data mining, thematic map design and topological analysis function of agricultural product information query, customers can query all enterprises of agricultural product configuration, parameters, performance, price and fine. E-business platform based on WebGIS can direct manage agricultural products production, sales, inventory, including product, and distributed information management, inventory management, logistics and distribution and online supermarkets many modules, all of it use B/S (Browser / server) architecture, and gradually developed as a model of agricultural products circulation using XML language development. It is as shown in figure 5. the farmland ecological environment and agricultural products safety auxiliary decision system based on GIS, including database, spatial database, model base and method base, knowledge base and so on, which is as shown in Figure 4. 
applied to intelligent control, namely agricultural machinery as long as the center and constitute a physical connection to the

high-speed network, can achieve two-way control required channel by a client browser. That is as shown in figure 6 .

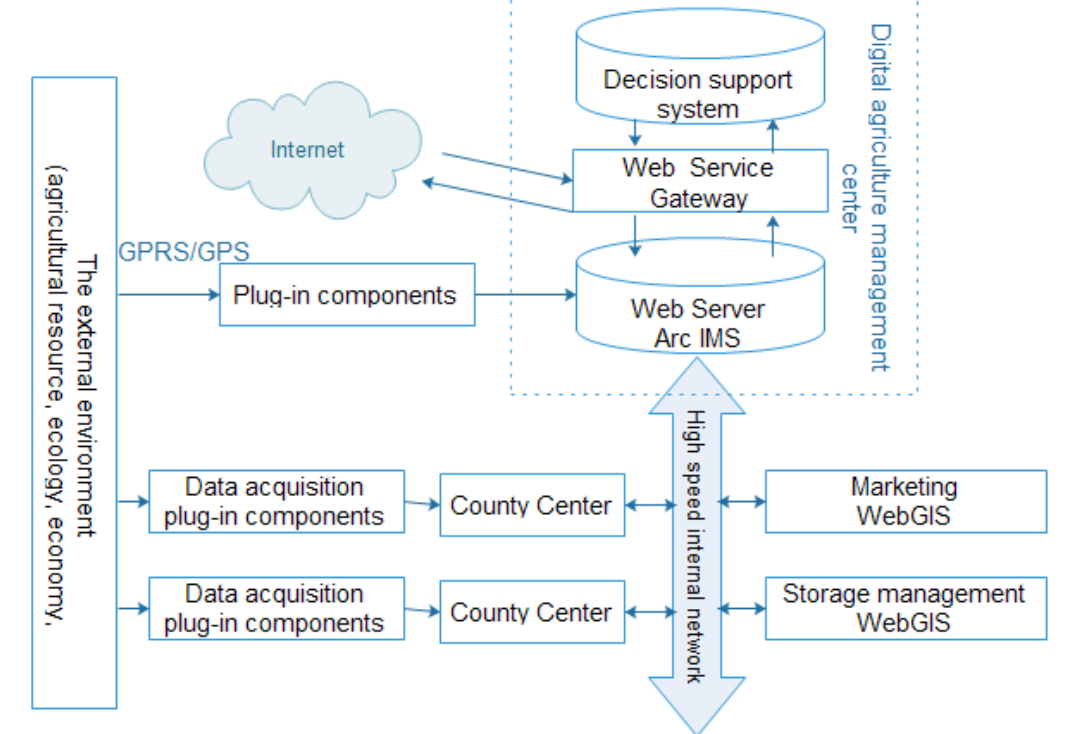

Fig.6 Digital agriculture spatial information management system based on the central nervous system control model

\section{Conclusions}

This paper studies the construction of agricultural information service platform. Around positioning and development goals, we put forward constructing a platform system with easy to use, practicability and expansibility principle, using .NET technology, SQL database technology and $\mathrm{B} / \mathrm{S}$ architecture, the system design platform interface layer, application layer and data layer. Integration of information resources, human resources and social economic resources, the agriculture information service platform were designed to 6 parts. And we set up column planning on each platform. At the same time, and design the background management system platform and safety control system, the backstage management system management system have one-stop management functions, can also manage and maintenance the news information, expert system, online consultation, administrators and other works, which can improve work efficiency.

\section{Reference}

[1] Han Xingshun, Pan Haifeng, Wen Jinghua. Evaluation on the development level of agricultural information service [J].Agricultural Mechanization Research, 2007.10:20-24

[2] He Bin, Zhang Lihou. Information management: Principles and methods [M]. Beijing: Tsinghua University press 2006.

[3] He Zhiyong, Cai Lecai, Li Hongchan. Study on agricultural information service system [J]. Journal of Sichuan University of Science and Engineering (NATURAL SCIENCE EDITION, 2009.22 (6): 50-53

[4] He Zhiyong. Regional agricultural information service platform [J]. Journal of Sichuan University of Science and Engineering (NATURAL SCIENCE EDITION), 2010.3:288-290 (298)

[5] Jin Yuxue, Chen Binglin. The demand analysis of agricultural information service in Wenzhou City [J].Zhejiang Agricultural Sciences, 2010.5:1145-1148. 